\title{
Names of Attitudes and Norms for Attitudes
}

\section{Inga Nayding}

\begin{abstract}
Fictionalists claim that instead of believing certain controversial propositions they accept them nonseriously, as useful make-believe. In this way they present themselves as having an austere ontology despite the apparent ontological commitments of their discourse. Some philosophers object that this plays on a distinction without a difference: the fictionalist's would-be nonserious acceptance is the most we can do for the relevant content acceptance-wise, hence such acceptance is no different from what we ordinarily call 'belief' and should be so called. They conclude that it is subject to the norms applicable to paradigmatic empirical beliefs, and hence, pace fictionalists, ontological commitments must be taken seriously. I disentangle three strands in the objector's thought: the 'What more can you ask for?' intuition, a linguistic/ conceptual claim, and a claim about norms. I argue that the former two are compatible with ontological deflationism, and therefore do not entail applicability of the norms. Nevertheless, if indeed there is no more robust acceptance with which to contrast the supposed nonserious acceptance, then the fictionalist's claim to austere ontology must be abandoned. Is there a reason to suppose there is any merit to the distinction-without-a-difference charge? I argue that there is, clarify it, and defend against objections, focusing on Daly 2008.
\end{abstract}

\section{Keywords}

Fictionalism, ontological deflationism, doublethink, make-believe, nonserious acceptance. 


\section{Fictionalism: two kinds of appeal}

Fictionalists claim that while they do not believe certain controversial propositions, for example, those entailing the existence of numbers, they accept them as useful make-believe. The attraction of fictionalism is not merely that it promises to make life easy by allowing you to disavow apparent existential commitments of theories you use. Its attraction is also in validating certain intuitions, such as that there is something wrong with seeing one's acceptance of the existence of numbers as answerable to reality in any way whatsoever, with being troubled by their "strangeness", or with being concerned about the lack of epistemic access to them. Fictionalism allows one to view the answers to such existential questions as ultimately within the purview of pragmatic reasons, beholden to nothing else. According to the fictionalist, the propositions we accept as mathematical truths should be seen as truths in a fiction, constrained only via the stipulations of this fiction. Those stipulations themselves, the source of basic ontological posits, either are or should be accepted as fiction - - in a way that does not amount to belief, and hence not subject to evidential norms. This allows one to have an ontology one could be proud of and not to have to worry about being forced into ontological commitments by the pressures of philosophical or scientific theorizing. The latter is important for those who are methodologically committed to viewing philosophy as continuous with science.

Some fictionalists might care more about the freedom to make existential claims as needed than about having an austere ontology. However, a view that completely abandons any claim to ontological advantages, moving under the "ontology does not matter" tent, thereby ceases to deserve the name of fictionalism, and should be classified as ontological deflationism. In view of that, I shall understand by 'fictionalism' a view that presupposes a contrast between

\footnotetext{
1 'Are' or 'should be' corresponding to the distinction between hermeneutic and revolutionary fictionalism, going back to Burgess (1983). This distinction will not play a significant role in the present discussion.
} 
serious and nonserious acceptance of the contents at issue. In other words, the fictionalist, to deserve the name, has to see herself as believing differently than the realist.

Although the prototype of the fictionalist's nonserious acceptance is to be found in ordinary displays of make-believe, such as games, daydreaming, etc., the fictionalist needs to press such acceptance into much more onerous service than it is doing there. It can no longer be fleeting and situation-bound as we often find it in everyday make-believe. It must be a fairly stable, dispositional attitude towards certain contents. One is to rely on it whenever philosophical ontology is not squarely in one's sights. There can be nothing like the amount of indeterminacy of literary fiction when it comes to what is true in the mathematical fiction. This, and not that, number is a solution to the equation, and therefore the need to accept that solution must be fully determined against the background of the relevant stipulations. The freedom, characteristic of make-believe, is to come only at the outmost "layer", where we posit the existence of the relevant kind, e. g., numbers, whereas the majority of specific mathematical acceptances appear to be no less constrained than specific ordinary beliefs. In this way, the fictionalist's acceptance comes to seem increasingly like belief, which gives rise to the concern that it really is belief masquerading under another name and that fictionalists are engaged in doublethink.

There appears to be no consensus among the fictionalists on exactly what must be done to deflect the charge of doublethink, and the tendency is towards doing increasingly less. Field claimed that mathematics' conservativeness makes it "legitimate to introduce mathematics as an auxiliary device that aids us in drawing inferences" (Field 1980: 2). Later, Yablo reasoned that if it is legitimate to claim the fictionalist attitude towards the deductively auxiliary, then it should also be legitimate to do so for the "representationally auxiliary" (Yablo 2005). If for Field the fictionalist had to isolate the content to which the fictionalist attitude is adopted, for Yablo what is put forth in full seriousness and what is a mere representational aid could be inextricably mixed (2001: 82; 2002: 299; 2008: 18). While Yablo himself makes a detailed case for regarding mathematical discourse as fictional, he also argues for the ubiquity of the fictional. However, if the fictional is as pervasive and ubiquitous as he alleges, one is left 
to wonder whether in the future it would be necessary to defend the fictional construal of any discourse at all, i.e., whether such a construal should not become the presumption.

\section{A sham attitude?}

The fictionalist makes apparently contradictory statements and claims that only one set of them expresses her true worldview. Her "true" ontology is austere, even as she makes all sorts of apparent ontological commitments when engaged in non-purely-ontological pursuits — pursuits that we would ordinarily count as serious, such as scientific research, rather than telling fairy tales to children.

There is the objector, whose intuition says that the fictionalist's "nonserious acceptance" is sham. But the fictionalist responds: "How so? Surely, we all do sometimes hold a nonserious attitude towards a content; Quine admits as much himself; ${ }^{2}$ so, why should we labor under a self-imposed constraint that serves no worthwhile purpose?"

The objector counters along some such lines as these: "Yes, no doubt, we do sometimes hold a nonserious attitude, but in such cases the nonseriousness is constituted in such-and-such a way, i.e., it is thisand-that that makes it the case that the attitude is nonserious, whereas in what you are proposing this is absent. Hence, you are invoking a distinction without a difference. The demands put on the attitude by the role you require it to play make it impossible to construe it as nonserious, make-believe, within-the-game acceptance. In no way does it fall short of serious acceptance. Hence your claim of nonseriousness is sham and your attitude is belief, plain and simple. That is why, when you turn around and deny what you have just said, and claim to have an austere ontology, you are nothing but a doublethinker. You ought to assume the responsibility that comes with believing."

Leave blank for now the particular analysis of nonseriousness. There are three distinct strands of thought tangled up in the little speech that I have put in the objector's mouth.

The first is that once you have accepted, say, the mathematical content, in the way in which the fictionalist proposes to accept it, there is nothing else for belief to be. You have done all you could

${ }^{2}$ Cf. Yablo 1998: 244-245. 
possibly do acceptance-wise. You could feel or fail to feel some inner glow; you could make passionate inward affirmations - or notnone of that is relevant, because none of that goes towards constituting belief. When it comes to what does constitute it, it is all there in the supposed nonserious acceptance, and therefore you make a verbal distinction where there is none in nature. (Not a perfect analogy, but compare with the story about the "stone soup": the trickster's project to make stone soup gradually evolves, through addition of nutritious ingredients, to the point where you get something which is misdescribed as "stone soup". By the time the fictionalist adds to everyday make-believe all that needs to be added, this is just plain belief, plus some irrelevant accompanying mental fluff.) The way to proceed from this intuition to something more solid is to show it entailed by an analysis of the distinction between seriousness and nonseriousness. We left that blank for generality's sake.

This idea, that there is nothing that the supposed fictionalist acceptance falls short of, is the core of the objector's thought - it is the doublethink charge proper. It is a thesis about the structure of our cognition. If true, the fictionalist's claim to austere ontology cannot be sustained. The contradictory statements will not float by each other on different levels of seriousness as the view seems to envisage, but will clash head-on, so to speak. Note that the thesis is descriptive and not normative. Note also that it is substantive in the sense that it is not about how something well understood is best described.

The second thread is concerned with the latter. It proceeds from the doublethink thesis and concludes that, therefore, the would-be fictionalist acceptance must be classified as 'belief'. This is a thesis about deserving a particular name. It is grounded in the idea that belief $=$ full acceptance. It is a thesis about concepts. Its defense would have to come from the analysis of nonseriousness which we left blank.

The above is easily confused with the third thread: that the kind of acceptance that fictionalism requires, whatever we call it, is answerable to certain norms and that those norms prohibit the adoption of this attitude for pragmatic reasons. If this is right, the fictionalist is not free to posit whatever is convenient whenever convenient, and that defeats the point of fictionalism, making "Fictionalism is impossible" a fair assessment. This third point is crucial for those who 
wish to insist on the importance of ontological commitments. The doublethink thesis is not sufficient for establishing that, as it is compatible with deflationism. A fictionalist who was persuaded by the doublethink charge could give up the idea of a contrast between the two attitudes, and with it the claim to an austere ontology, but insist on freedom to accept certain existential statements as needed in science. (Thereby such a fictionalist would turn into a deflationist.)

To recap, in brief, these are three separate theses: (1) The envisaged fictionalist acceptance amounts to full acceptance of the relevant content. In other words, nothing less than full acceptance will satisfy the demands fictionalism puts on the relevant acceptance attitude. (I call this 'the doublethink thesis/charge/objection'.) (2) Full acceptance is belief. (3) Fictionalist acceptance is subject to certain norms, namely, the same norms as apply to paradigmatic cases of belief. What reason is there to hold (3)? Or rather, what reason is there to hold (3) that has anything to do with (1) and (2)? (If there is another reason, it is outside the scope of this paper.)

Perhaps one thinks: if full acceptance is belief, then it is subject to the norms that belief is subject to, and those, as we all know, are evidential norms. But certainly this is question-begging. If full acceptance deserves to be called 'belief' and it is a point of dispute just what norms full acceptance is answerable to, then it hardly helps to say that it is answerable to the norms that belief is answerable to. Those are ex hypothesi also in dispute. (The hypothesis here is that belief $=$ full acceptance.)

Some philosophers think our concept of belief is normative, i.e., that it comes with a norm (or some norms) already in it. ${ }^{3}$ (I shall assume these are the very same norms that generate the responsibility for ontology.) There is some supporting intuition in favor of this. If so, then indeed (1) and (2) would entail (3). But 'full acceptance' in (1) cannot be a normative notion, and hence, if 'belief' is normative, then (2) should be rejected. 'Full acceptance' in (1) cannot be normative because it aims to characterize acceptance as understood by the fictionalist, whereas the fictionalist cannot reasonably take it to be a normative notion. That is because the notion of seriousness at play cannot be normative. Suppose it were. Then the fictionalist who says,

${ }^{3}$ Shah 2003, Shah and Velleman 2005. 
"I am not committed to the truth of what I am asserting here because I am not being serious, because I put it forth in the spirit of makebelieve, etc." would not be adverting to any psychological reality, but rather would be merely saying that she refuses to be answerable to the relevant norms. That would constitute coming full circle to the bad pre-Quinean days, when philosophers allegedly were given to saying things like, "In assessing my ontology, don't count what I say there, count only what I say here," and leaving it at that.

Let us then assume that 'belief' is not a normative concept and, for the sake of the argument, let us take (2) to be true. We can return to the question posed earlier: do (1) and (2) provide any kind of reason for (3)? My answer is "No". It follows from what I have already said: (1) is compatible with deflationism, whereas (2) is simply a conceptual or terminological claim that should not make a substantive difference.

\section{Common confusions}

Why does it seem that (3) follows? It could be that the use of 'belief' is fluid and oscillates between a normative and a non-normative sense (as I suggested elsewhere ${ }^{4}$ ). This could account for a slide from (1) and (2) to (3) through ambiguity in (2).

Alternatively, the confusion could stem from a misunderstanding of the role of paradigmatic cases of belief for the issues at hand. This appears to be both widespread and pernicious and so deserves a somewhat extended discussion, which will take up the rest of this section.

There is a tendency to think that by pondering the clearest cases of belief (i.e., of full acceptance, as we agreed), one discovers the true nature of belief: in effect, its essence. Such paradigmatic cases are supposed to be the ordinary empirical beliefs. Their essence, let us suppose, somehow triggers the application of the relevant norms. One would need to conclude that this essence is present in any case of belief. It would not help to propose that 'belief' is a natural kind term for which the familiar empirical beliefs play the role of reference-fixing samples, that is, to think along the lines of the following.

\footnotetext{
${ }^{4}$ Nayding 2011.
} 
"We already found out what belief really is, just like we found out that water is $\mathrm{H}_{2} \mathrm{O}$. Just as by conceding something is water, you are conceding that it is $\mathrm{H}_{2} \mathrm{O}$, so by conceding an attitude is belief, you are conceding that it has an essence that makes it subject to those norms." The mistake here is transparent: just as you should not concede something is water unless you know it is $\mathrm{H}_{2} \mathrm{O}$, so too, if you are committed to belief having a certain norm-triggering essence, you should not concede that an attitude is belief unless you ascertain its presence.

It might be said that, nevertheless, those clear cases create a presumption that the same norms apply: after all, why would not the same norms apply to the same kind of thing (i.e., to full acceptance, also known as belief)? This too is mistaken. Those clear cases might well co-instantiate several kinds, with the norms applying to one kind and not others. An analogy: perhaps the clearest cases of moral demands relate to objects that are both rational and capable of experiencing pain. In order to project the norm to other cases, one must come to understand which kind is relevant: which one of these properties triggers the applicability of the norm.

It seems that when it comes to belief this simple point is obscured because one can discern but one relevant kind: belief. We should distinguish, however, the fullness of acceptance (i.e., there being nothing further that could be done acceptance-wise) and whatever this acceptance consists in. These could diverge. I will dwell on this a little.

Consider an analogy. It is possible for there to be norms that prescribe conditionally on the absolute quantity of water in one's possession, and it is possible for there to be norms that prescribe conditionally on the fullness of the glass. E.g., you might be required to share whenever you have $250 \mathrm{ml}$ of water, because that is the absolute quantity of water you have, or you might be required to share whenever your glass is full, because of that very condition and regardless of the capacity of the glass. If you have a full glass containing $250 \mathrm{ml}$, you are required to share whichever of these possible norms is in fact the norm. However, it matters which of the two is the actual norm, because that determines what to expect in other cases. If fullness as such is what grounds the norm (i.e., is what figures in the content of the norm as the relevant condition), then ceteris paribus you have an 
obligation when you have a smaller glass which is full with only $200 \mathrm{ml}$ in it. Not so if the other possible norm is the actual norm. Vice versa, the norm based on the absolute quantity would create an obligation when you have $250 \mathrm{ml}$ in a half-filled larger glass.

Similarly, it is possible that the norms applicable to full acceptance are predicated upon its fullness as such (i.e., upon there being nothing further to be done acceptance-wise) or that they are predicated upon what the acceptance of the relevant content is in itself, i.e., upon what it consists in. Which of these possibilities obtains cannot be determined by pondering cases where either norm would apply, such as beliefs about ambient tables and chairs.

What do I mean by 'acceptance as it is in itself' or by 'what it consists in'? The idea is not that acceptance is something separable from the content that it is the acceptance of. On the contrary, I would like to underscore that acceptance is always acceptance-of-a-content. Nevertheless, there is something that this acceptance-of-a-content consists in for a given content. It is that which is to full acceptance of a given content as the absolute quantity of water is to its completely filling the glass. For example, if acceptance is a sui generis feeling, then it is that feeling. Perhaps it can vary in intensity, and then it could be that for one content the maximal reachable intensity is $\mathrm{M}$, while for another it is $\mathrm{N}$. Then acceptance of the same intensity could be maximal for one content and not for another. Alternatively, maybe acceptance consists in dispositions towards use. (I say 'use' in the most general sense, comprising mental use.) Likewise, then, such and such dispositions that go into acceptance of a given content $C$ may or may not constitute the maximal, i.e., complete, acceptance of $C$.

It should be clear now that, depending on what grounds the norms (i.e., which properties of acceptance are implicated in the content of the norm: its completeness or something else), it may or may not be the case that the same norms apply to any acceptance that is, in the relevant sense, "complete". Suppose acceptance is "use" (in some relevant sense), and suppose the content $C 1$ lends itself to three kinds of use $U 1, U 2, U 3$, while the content $C 2$ lends itself to only one kind of use, U1. If the norms stem from completeness of acceptance vis-à-vis the kinds of use, then the same norms would apply to the full acceptance of $\mathrm{Cl}$ and $\mathrm{C2}$. But if the norms stem from the kind of 
use as such, then that might not be the case. Furthermore, it might then turn out that the same norms apply to $C 2$ as to a partial acceptance of $\mathrm{Cl}$ (one comprising only $U 1$ ).

A brief point of clarification. If acceptance consists in dispositions to use, then there is a very finely grained notion where every content would have an individuating profile and there is also a very high-level description ('act as if true') which will be invariant across contents. I am suggesting that there may be an intermediate level where systematic differences could be discerned. For example, some contents can be incorporated into a "map" which is continuous with the map of our environment and thus ultimately with the sensory content, ${ }^{5}$ while others cannot be so incorporated (purely mathematical contents, for example). This incorporating presents a kind of use that appears to be available for some contents and not for others. In this way, it is prima facie possible that different norms apply to full acceptance of such contents than to full acceptance of other kinds of contents.

To sum up, the claim that full acceptance deserves to be called 'belief' should not lead one to conclude that full acceptance is always subject to the norms that apply to it in a range of familiar cases of belief/full acceptance, specifically, evidential norms or norms requiring parsimony of existential posits. Therefore, the fictionalist who is more of a deflationist at heart - one who cares primarily about validating the intuition that there is something wrong with taking ontology seriously — can maintain that part of the view while granting to the objector that the acceptance of the relevant contents does not contrast with any more robust acceptance and hence giving up the insistence that she really is ontologically austere.

Of course, the mere fact that one could concede something is no reason to think one should. Is the doublethink objection anything for the fictionalist to worry about? I cannot give this subject an exhaustive treatment, but I would like to discuss Daly 2008, since it is often thought to have dispatched the doublethink worry. Daly does not endorse fictionalism, rather, he defends it from this objection to press another, but the latter will not concern me. The discussion will serve to illustrate several common misconceptions. I will then try

${ }^{5}$ I am alluding, of course, to the treatment of belief in Armstrong 1973. 
to improve on the presentation of the doublethink charge to prevent such misconceptions.

\section{Daly 2008 - summary of the argument}

Daly starts by summing up his understanding of fictionalism as the proposal to "exploit" rather than to believe the relevant proposition. He underscores that instead of believing some proposition $P$ the fictionalist merely believes it to be useful. Daly then approaches the doublethink worry via a passage from O'Leary-Hawthorn (1994) where the latter points out that the fictionalist's characterization of the would-be fictionalist attitude coincides with the usual characterization of belief. Having objected to what looks like a behaviorist take on that characterization, Daly nevertheless acknowledges that there must be a difference between belief and the fictionalist attitude and cites Rosen and Burgess (2005) to this effect. Daly responds that such a difference is plain for all to see: the person who adopted the fictionalist attitude to $P$ would typically say that he does not believe $P$, for example. This ushers in a discussion of Horwich (1991) who claims that such professions of disbelief are merely expressions of mistaken self-attribution on the fictionalist's part. Daly's response is three-pronged, as follows. First, this puts the fictionalist in a nowin situation. Second, Horwich contradicts his own views on truth. Third, under the heading 'Aren't we all jobbing fictionalists?' Daly advances the master-argument: we all admit there is a fictionalist attitude, so that is the attitude that the fictionalist is talking about. As Daly is aware, Horwich anticipates this move and draws the distinction between local and global fictionalism, objecting only to the latter. Daly makes two points to counter this. First, he offers a counterexample: the intentional stance towards chess-playing computers. He takes such an intentional stance to provide us with an example of global fictionalism. Secondly, Daly charges that Horwich is guilty of ignoratio elenchi. "What is at issue?" Daly asks, and answers that it is whether there is a distinction between believing a sentence and exploiting it. According to Daly, even qualified, local fictionalism gives 
us a reason to accept that there is such a distinction. Daly concludes the relevant part of the paper with brief remarks on Blackburn and Teller, with which I will not concern myself here, since they do not add much to the substantive points made earlier.

The problem with Daly's treatment is threefold. First, his presentation of the fictionalist attitude as nondescript "exploiting" of propositions is overly broad and fails to acknowledge that it involves the use of the very same content the use of which can constitute belief. Second, he appears to misunderstand Horwich's distinction between local and global fictionalism, construing it as a matter of the scope of the subject matter rather than of the scope of use of the relevant content. Third, his master argument presupposes a misunderstanding of the role of paradigmatic cases along the lines I sketched earlier.

I will take up the issues in the order that helps better untangle them: (i) recap the doublethink charge in Horwich's rendition; (ii) discuss why Daly's characterization of fictionalist acceptance is inadequate; (iii) dismiss Daly's charge that Horwich contradicts his own views on truth; (iv) discuss what is at issue, and what I think Horwich was getting at with the local vs. global fictionalism distinction, and hence why Daly's counterexample misses the point. I will then (v) offer my own critique of Horwich's conception (or presentation) of the distinction between serious and nonserious acceptance and propose a better way to think about it; (vi) show how the charge of doublethink can be supported by this conception of the distinction; (vii) revisit, in light of the above, Daly's "readily forthcoming behavioral difference" between the fictionalist and the realist. I will put (v)-(vii) into a separate section since the bulk of it is not a direct critique of Daly.

\section{Doublethink charge as advanced by Horwich}

The discussion of Horwich 1991 is the centerpiece of Daly's argument, as Horwich offers the most sustained defense of the doublethink objection to fictionalism. Referring to fictionalism as 'instrumentalism', Horwich wrote:

I will try to show, not just that one should not follow [instrumentalism's ultimate recommendation], but that one cannot. This is because it 
presupposes a distinction between, on the one hand, believing a theory and, on the other hand, being disposed to use it, or, in van Fraassen's terminology, merely accepting it. But there is no such distinction, or so I will argue. Believing a theory is nothing over and above the mental state responsible for using it; and so the attitude urged by instrumentalism is impossible. (Horwich 1991: 2)

The 'what more do you want?' theme, which we identified earlier, comes across very clearly. Horwich urges the reader to “... bear in mind what it is to accept a theory, and then try to say what more would be involved in believing it" (Horwich 1991: 3). This is backed up by the following remarks:

...when a theory is regarded instrumentally in normal scientific practice, it is always understood that its use is to be confined to a certain range of applications. It is understood that only predictions in a specified domain should be relied upon, and use of the theory in conjunction with other theories is also severely constrained...Thus, there is a crucial difference between the sort of acceptance involved in general, philosophical instrumentalism, and the attitude we have towards particular theories treated instrumentally for particular purposes. Consequently, our familiarity with qualified, local instrumentalism gives us no reason to acknowledge the conceivability of unqualified, general instrumentalism. (Horwich 1991: 4-5)

Note the distinction between local and general instrumentalism at the end of the quoted passage; we shall take it up later. I will sometimes follow Horwich's usage and call an acceptance 'instrumental' interchangeably with 'nonserious'. I will say 'fictionalist acceptance' to refer to such (supposed) nonserious acceptance as satisfies the requirements of fictionalism.

\section{Fictionalist acceptance and beliefs in fictional truth}

Daly uses the term 'exploitation' for the nonserious acceptance. I will do likewise when engaging with his text; however, I prefer 'nonserious acceptance'. 'Exploitation' is too broad. I think it is fair to say you exploit a sentence if you use it as a mnemonic device to remember the order of colors in the rainbow. But that is not the sense of 'exploit' that the fictionalist can adopt. The fictionalist has to use propositions of the theory as premises in arguments whose conclu- 
sions she will accept. In this sense she accepts or pretend-accepts the content of those propositions.

It is true that some fictionalists, starting with Field 1980, sometimes wrote as if they merely meant to replace accepting that $P$ with accepting 'In the fiction $F, P$ '. However, this is not a tenable view. The difference has to be in the kind of acceptance, not in what one accepts. Some of the reasons why are spelled out in Yablo 2001 and lead him to conclude that "The fiction . . . functions as medium and not message." (Yablo 2001: 76). (I take him to present the most thoughtful and clear version of fictionalism.) Even if it were a tenable view, the doublethink objection could still be pressed, but from a different angle, along the lines of the following. "What makes it the case that you accept the content that you say you accept, i.e., 'In $F$, $P$ ', rather than just $P$ ? You use the former in almost all the ways you would use the latter if you were a realist. Maybe 'in $F$ ' is just a kind of soothing mantra, devoid of genuine meaning? Maybe, in light of that, if you say 'not-P' you are a doublethinker." Thus, the issue of attitudes is unavoidable. I suggest we proceed focusing on the clearer and better version of fictionalism and look for the difference in the attitude and not in the content.

Daly's statement of fictionalism tends to obscure the fact that the fictionalist purports to adopt the fictionalist acceptance attitude to the relevant content. It thereby obscures the very source of the doublethink objection. Daly states merely that the fictionalist does not believe that $P$ but believes something else entirely, thus leaving the fictionalist acceptance out of the picture. No wonder then that the doublethink objection seems well-nigh nonsensical to him.

Being a fictionalist about mathematics, then, involves not believing sentences such as ' $7+5=12$ '. Instead, the mathematical fictionalist believes such sentences as 'according to standard mathematics, $7+5=$ 12 ', and '“7 $+5=12$ ” is a useful sentence'. (Daly 2008: 424)

Notice 'instead'. What follows it, however, is not what the fictionalist does instead. Those who believe that $7+5=12$ typically also believe it to be useful and true according to standard mathematics. Clearly, 'merely' is omitted, but this is a trifling point. The important point is that the fictionalist cannot make do with merely believing this sentence useful; she will need to be using it, e.g., as a premise 
in scientific reasoning. One could try a detour, via (i) 'using $P$ as a premise would produce the correct result' and (ii) 'if $P$ then $Q$ '. From there you would go: (iii) 'if I use $P$ as a premise, the result would be $Q$ and it would be correct'. And then you conclude: 'therefore, $Q$ '. I say that if you concluded so - if you got to $Q$ - then you have used $P$. The burden of proof is on those who reject this.

We can see that this is indeed a misconception and not merely a misstatement on Daly's part from his charge that Horwich equates the belief that $P$ with the belief that ' $P$ ' is useful and thereby contradicts his own views on the nature of $\operatorname{truth}^{6}$ (Daly 2008: 429). In fact, it is clear that Horwich claims that there is no difference between the belief that $P$ and the (certain kind of) use of the proposition that $P$; in other words, that there is no difference between the belief that the theory is true and the use of that theory (i.e., the "unrestricted" use). The use of something is not the same as the belief that it is useful. ('Use' here need not mean anything physical or observable. It can be as mental as you like.) This misconception informs Daly's other objections in subtler ways. I will not focus on this explicitly, letting it emerge instead.

\section{What is at issue?}

Consider another objection Daly puts forth.

...Horwich's conclusion is an ignoratio elenchi. What's at issue - and as Horwich originally presented the issue - is whether the fact that we use some theories for practical purposes without believing them is a reason 'to think that belief and acceptance are distinct attitudes'. In other words, the issue isn't whether qualified, local fictionalism gives reason to think that unqualified, general fictionalism is conceivable. The issue is whether even a qualified, local fictionalism gives reason to

${ }^{6}$ Here is the relevant passage: "The fictionalist distinguishes between: (1) Theory T is true; and (2) T is useful. According to the fictionalist, one can believe (2) without believing (1). Horwich disagrees. He claims that to believe (1) just is to believe (2), because 'belief simply is acceptance'. They are the same belief state. Belief states are identical only if their contents are identical. So Horwich is committed to claiming that (1) expresses the same content as (2). That, however, is incompatible with Horwich's (entirely plausible) rejection of the pragmatic conception of truth.” (Daly 2008: 429) 
think that there is a distinction between believing a sentence and exploiting it. And it surely does, because qualified, local fictionalism just is - as its name suggests - fictionalism about a localized and qualified subject matter. To be a fictionalist about a collection of sentences is to exploit, not to believe, the sentences in that collection. Unless there is a distinction between belief and exploitation, there can be no form of fictionalism whatsoever, including, a fortiori, a qualified, local fictionalism. (Daly 2008: 431-2)

There are two straw men set up here. One is misconstrued Horwich, who by 'local fictionalism' means 'fictionalism about a localized and qualified subject matter'. It is clear that for actual Horwich it is, rather, the use that is supposed to be "local", as opposed to "global", in order to constitute nonserious acceptance, i.e., such use is supposed to be somehow bounded or circumscribed. This idea is not as clear as one might wish, but that should not lead us to adopt Daly's construal, which leads him to offer as a counterexample the pervasive intentional stance we adopt to chess-playing computers. (Daly 2008: 431). We certainly do not treat a personal computer in all respects, in all contexts, as more than a mere machine — think of the computers waiting by the curb for trash collection. As I understand Horwich's idea, such cases would suffice to show that the use of 'Computer is a person' is confined, bounded, and that its interaction with other theories (such as our emergency preparedness plans) is restricted.

The second straw man apparently denies that there is any distinction between serious and nonserious acceptance at all. Such a view is absurd: surely, there are plenty of entirely uncontroversial cases of nonserious acceptance. Every time we play a game or assume something provisionally we have a nonserious acceptance. Daly thinks he finds therein an easy proof that the distinction between belief and exploitation is well-grounded and that, therefore, Horwich's concerns are misplaced. His proof comes to this: "Pretty much everyone should admit the distinction because pretty much everyone draws it" (430). Daly elaborates:

There are many things you exploit without believing them. You exploit a computer's wanting to get its king's bishop out early, or the sun's rising, or electricity's flowing along cables, and yet you believe none of these things. Again, it's common practice in science to exploit talk of frictionless planes, perfectly inelastic bodies, and the like with- 
out believing that talk. So mustn't the distinction between belief and exploitation be well-grounded since we frequently and more or less consciously draw it in our own cognitive lives? Aren't we all jobbing fictionalists? (Daly 2008: 431)

What is really at issue is whether the acceptance attitude toward the relevant range of cases, e.g., the mathematical, which meets the fictionalist requirements, could count as nonserious. As discussed, the central question here is whether there is any kind of more complete or robust acceptance for such contents. The sense in which the clear cases show that the distinction is well-grounded is just that: in those cases it is not a distinction without a difference, but rather there is something that constitutes the difference.

Perhaps one thinks, "Let me focus on what I do mentally when I pretend there are frictionless planes, and let me do the same with the proposition that there are numbers. That will be my instrumentalist acceptance of that proposition. Now, to illustrate the contrast, let me focus on what I do when I believe there is a table in front of me. If I adopt the same attitude to the existence of numbers, then I would surely have a different-non-instrumentalist - acceptance of their existence."

This might work if attitudes were sui generis feelings. But if the distinction between the fictional and the serious acceptance is along the lines of partial/complete, as suggested by Horwich, then, as we saw, the 'same' is open to different readings. One would have to know which sameness to aim at: sameness with regard to completeness or sameness with regard to the constituent dispositions to use. If the dispositions involved in the provisional acceptance of frictionless planes constitute the minimum required to "do the work" that the fictionalist needs done in the case of numbers, then one is bound to fail in an attempt at an incomplete acceptance of numbers within those constraints. Likewise, one might be bound to fail in an attempt to have the very same set of dispositions with regard to the number-content as with regard to the table-content, simply because the former might not lend itself to all the same kinds of use as the latter. In other words, one might only be able to succeed in an attempt that would bring about the acceptance (of numbers) that is the same as the acceptance of frictionless planes in the sense of the constituent 
dispositions and the same as the acceptance of tables in the sense of completeness. Thus, though in each case one would succeed in an attempt, the attempts would not result in two non-identical attitudes to the target content.

\section{Horwich's analysis}

I noted that Horwich's idea that nonserious acceptance is somehow incomplete is not very clear. He has to share some of the blame if Daly misconstrues him. We find more difficulties with the account on closer inspection. It seems 'restricted' use should not be taken to mean 'narrow'. After all, 'narrow' is a matter of degree, whereas accepting instrumentally is not supposed to be. If we set aside any suggestion of narrowness, a deeper problem emerges. Suppose you believe that not- $P$ and are working on a task for the purposes of which you instrumentally accept that $P$. Your acceptance that $P$, ex hypothesi, is "restricted" to that task. But you do not cease to believe that not$P$ even as you use $P$ for the purposes at hand. Somehow you accept not- $P$ contemporaneously. If you do not, your acceptance of not- $P$ is restricted, and hence instrumental. So, either you accept both $P$ and not- $P$, which prima facie does not look good, or you accept neither, which is contrary to the supposition that you accept $P$. (I do not find any help in the idea of simply adding awareness, which may be suggested by Horwich's phrase 'understood to be restricted' [my italics].)

\section{Towards a better understanding of the distinction}

When you accept something provisionally, in a game, or as a simplifying assumption, your beliefs continue to operate "in the background". You try to make sure you do not rely on the instrumentally accepted in ways you did not intend, and such monitoring is done through beliefs. This suggests a two-tier picture of acceptances, with instrumental acceptance working against the background of belief. Trying to articulate this intuitive picture appears to be the only way forward. 
We need a way to understand the distinction between the "background" and the "foreground" if we want to say that we continue to accept what we believe "in the background". A first thought might be that the background acceptance is constituted by counterfactuals: if I accept something nonseriously, then there are some other circumstances where I would not accept it, even though they would not change my evidential base. However, this is clearly inadequate, because, equally, if I seriously accepted that $P$, there may well be some circumstances where I would cease to accept it (and accept not$P$ instead): the circumstances which would trigger the adoption of a nonserious attitude. We need to make this asymmetrical: only some counterfactuals should count.

Our intuitions about whether someone is serious (or sincere) in holding a belief (or another attitude) seem to be informed by our beliefs about how that person would behave in certain specific situations, that appear to us as "probative" for a given attitude (taken with its object). "Does she only pretend to love him? - Would she continue to act as if she does if he did not have any money?" "Does he only pretend that the computer is a person? - Would he show any concern for it if fire broke out in the house?-Well, maybe he does not show any concern for human persons either? - Then maybe there is no matter of fact as to whether he really believes the computer is a person." Such intuitions are far from capturing the full complexity and all the nuances of our thinking about our real-life attitudes. They ignore our being compartmentalized and conflicted. Nevertheless, they might capture as much as is clear in the concept itself and serve well enough for our rather narrow focus on fictionalism and the doublethink charge. A scientist who habitually works on scientific problems assuming frictionless planes would nevertheless reintroduce friction into the model if she realized that the problem requires a greater degree of precision. We can suppose this to be partially and defeasibly constitutive of the nonserious attitude in this case (counting situations requiring greater degree of precision as probative for such content). In other words, we can suppose that there is a set of counterfactuals of this kind, such that a sufficient proportion of them holding true is constitutive of nonseriousness of acceptance of 
a given content, while not each individual one is necessary. ${ }^{7}$ The set of probative circumstances will, obviously, depend on the specific content of the attitude in question. The prima facie difficulty is that the subject's desires and values, as well as her other beliefs, must also be seen as parameters that determine that probative set. Does reference to other beliefs amount to an objectionable circularity? It need not if there is a sufficient range of cases that are not in question. You need not expect always to find yourself in a situation where in order to show that the subject's acceptance that $P$ is serious you have to show her acceptance that $Q$ is serious and vice versa. And if you were to find that to be the case, your intuitions about seriousness would falter.

\section{Contrast collapse}

This analysis of the distinction would support the doublethink charge if one found oneself at a loss to think of probative situations showing that what is alleged to be instrumentally accepted is not "really" accepted.

What would be a situation where the use of mathematics would count towards its acceptance "in earnest"? I do not wish to suggest that our serious concerns are all of the gross down-to-earth kind. One cares also about Truth. We know of many people who made great sacrifices for what they saw as the truth, and we certainly think they were serious. Nevertheless, in such circumstances we would attribute belief even if we could not make any sense of its content. Thus, it could be that the attribution is purely deferential, where we simply go along with the person's self-attribution, just as an attribution of content could be purely deferential in certain cases. Furthermore, even under the most favorable assumptions, bravely standing up for the truth is at best a sufficient, but not a necessary, condition of belief. Adhering to a philosophical view ought to be compatible with fairly modest degrees of fortitude. Thus, the fact that we attribute seriousness in such cases does not show that we understand what it is to be serious and so does not put to rest the concerns animating the

${ }^{7}$ It could be a bit more complicated, with different individual counterfactuals having different weight. In that case read 'proportion' accordingly. 
doublethink charge against fictionalism.

Why not simply say with Daly the following?

If a behavioural difference is wanted, then it is readily forthcoming. Someone who believes theory T will typically say, 'I believe that T; I don't only believe that $\mathrm{T}$ is useful'. By contrast, someone who exploits T will typically say, 'I don't believe T; I believe only that it is useful'. (Daly 2008: 428$)^{8}$

This statement seems again to evince Daly's tendency to conflate the belief in usefulness of a theory with its actual use. If we set this aside, we might read this as advising to look at self-attribution. I assume that one would be unwilling to make object-level avowals presupposing the existence of numbers in very same contexts where one likes to assert that one does not believe in numbers. The alternative is to suppose that fictionalism might have its sole expression in an odd disposition to make pronouncements in the form of Moore's Paradox. It is hard to see how such a disposition could reassure us if we suspected the fictionalist of doublethink. Any suggestion to this effect one could get from the quoted passage should be set aside, I think.

Still, looking at the object-level avowals, why not simply say that one who accepts mathematics seriously would be disposed to freely acknowledge the existence of numbers in certain circumstances: perhaps, at leisure, on reflection, etc., whereas one who accepts it nonseriously would not? The problem with this idea is that both the fictionalist and the platonist would on many occasions find themselves saying the very same things: that there are infinitely many primes, etc. We would need somehow to mark off the avowals that are made seriously in order to distinguish the fictionalist from the platonist. (Clearly, we cannot simply say "if one is serious", nor "if one takes oneself to be serious", as that would beg the question.) It will not do to say the subject must be focused and thinking hard, because a fictionalist might be thinking hard about a mathematical problem,

\footnotetext{
${ }^{8}$ This passage is Daly's rejoinder to Rosen and Burgess (2005: 536). Unfortunately, they seem to share Daly's idea about the significance of self-attribution, as they grant that if scientists were indeed given to frequent verbalizations of the kind Daly suggests, then the doublethink objection would have less merit. I disagree with that, for reasons stated. If disavowals could do the trick, it would be of no consequence whether philosophers or scientists performed them, in my view.
} 
thus presupposing the existence of numbers for the purposes at hand. It will not do to go the opposite way and say that the subject must be relaxed and not troubled by any immediate mathematical concern: the subject might nevertheless be in a state where the mathematical make-believe is dispositionally operative. (A fictionalist is lying in a hammock under a palm tree, pondering the starry sky above and the moral law within, when she hears, "I wonder how many primes there are?" She might not be disposed to challenge the presuppositions and might well respond, "Infinitely many".) The subject needs to be engaged not simply "in reflection", but "in reflection on what there is".

Herein lies the problem. What constitutes a true instance of reflection on what there is - as opposed to reflection on what there is fictionally? We could say: in the former we set aside any presuppositions. But to set aside all presuppositions just is to be serious. ${ }^{9}$ Then we are back to the question of what constitutes being serious. Furthermore, the thought that there is a cognitive activity of "reflection on what there is" distinct from ordinary theory choice runs counter to the Quinean understanding of ontology that underlies indispensability arguments, the raison d'être of fictionalism. Of course, one might be engaged in a cognitive activity that one thinks of as such reflection, as peering into the fabric of reality, but this being an illusion, the avowals made on such occasions, contradicting the avowals made in more practical contexts, would be instances of doublethink.

Daly complains that the fictionalist is placed in a "no-win situation": no matter what he says, "[i]t is claimed that [he] is in the same psychological state as the believer — namely, that of belief - and it is just that [he] is in the grip of a delusive theory and so misreports his belief as something other than a belief" (Daly 2008: 429). Thus, "It transpires that nothing would be interpreted [. . .] as evidence for someone's being a fictionalist" (Daly 2008: 429). This complaint is not to the point, because we are not talking about evidence. Rather, we are trying to understand what it is for someone to accept mathematics instrumentally. We are trying to understand how the supposed state of instrumental acceptance, as invoked by the fictionalist,

\footnotetext{
${ }^{9}$ I am not saying that we would ordinarily only call someone serious only if he literally set aside all presuppositions. This is contextual, cf. 'Knowing that $P$ is excluding all possibilities that not-P'.
} 
differs from the non-instrumental acceptance of the same content. We cannot take the fictionalists at their word if we do not understand what they are saying. We can, of course, assess that a person is sincere even if we do not understand, but being sincere does not keep one from being confused or from invoking a distinction without a difference.

I conclude that Daly's discussion does not offer anything that could allow the fictionalists to dismiss the suspicion that the nonserious acceptance they are proposing cannot be contrasted with serious acceptance of the same content. If indeed it cannot be, there remains a separate question whether anything like the norms that apply to empirical belief apply to acceptance in such cases. If they do not, one could enjoy ontological freedom without the ability to claim an austere ontology. ${ }^{10}$

Inga Nayding

inga.nayding@gmail.com

\section{References}

Armstrong, David M. 1973. Belief, Truth and Knowledge. Cambridge: Cambridge University Press.

Burgess, John P. 1983. Why I am not a Nominalist. Notre Dame Journal of Formal Logic 24: 93-105.

Daly, Chris J. 2008. Fictionalism and the Attitudes. Philosophical Studies 139(3): 423-440.

Field, Hartry. 1980. Science without Numbers. A Defense of Nominalism. Princeton: Princeton University Press.

Horwich, Paul. 1991. On the Nature and Norms of Theoretical Commitment. Philosophy of Science 58: 1-14. Reprinted in his From a Deflationary Point of View. Oxford: Oxford University Press.

Nayding, Inga. 2011. Conceptual Evidentialism. Pacific Philosophical Quarterly 92: 39-65.

O’Leary-Hawthorne, John. 1994. What Does van Fraassen's Critique of

${ }^{10}$ The central idea here goes back to my dissertation, so I would like to thank Paul Benacerraf for doing what he could to help me develop it at the time, as well as for his recent helpful comments. Its presentation went through several transformations, and I am grateful to everyone whose criticism led to the paper taking its present shape. I am very grateful to the anonymous referee for Disputatio whose comments helped clear up several obscurities and improve the paper. 
Scientific Realism Show? The Monist 77: 128-145.

Rosen, Gideon and Burgess, John P. 2005. Nominalism Reconsidered. In The Oxford Handbook of Philosophy of Mathematics and Logic, ed. by S. Shapiro. Oxford University Press, 515-535.

Shah, Nishi. 2003. How Truth Governs Belief. Philosophical Review 112: $447-$ 482.

Shah, Nishi and Velleman, J. David. 2005. Doxastic Deliberation. Philosophical Review 114: 497-534.

Yablo, Stephen. 1998. Does Ontology Rest on a Mistake? The Proceedings of the Aristotelian Society Suppl. Vol. 72: 229-261.

Yablo, Stephen. 2001. Go Figure: A Path Through Fictionalism. Midwest Studies in Philosophy 25: 72-102.

Yablo, Stephen. 2002. Abstract Objects. A Case Study. Nô̂s 36: 220-240. Supplement: Philosophical Issues, 12, Realism and Relativism, 220-240.

Yablo, Stephen. 2005. The Myth of the Seven. In Fictionalism in Metaphysics, ed. by M. Kalderon. New York: Oxford University Press, 88-115.

Yablo, Stephen. 2008. The Truth and Something but the Truth. Carl G.

Hempel Lecture at Princeton University. Reprinted in Aboutness. Princeton: Princeton University Press, 77-95. 